\title{
COMPARATIVE STUDY OF CAUDAL ROPIVACAINE WITH CAUDAL ROPIVACAINE AND DEXMEDETOMIDINE IN PEDIATRIC LOWER ABDOMINAL SURGERIES
}

\author{
Monika Gandhi ${ }^{1}$, B. K. Ved ${ }^{2}$, N. Rajakumari ${ }^{3}$
}

\section{HOW TO CITE THIS ARTICLE:}

Monika Gandhi, B. K. Ved, N. Rajakumari. "Comparative Study of Caudal Ropivacaine with Caudal Ropivacaine Dexmedetomidine in Pediatric Lower Abdominal Surgeries". Journal of Evolution of Medical and Dental Sciences 2014; Vol. 3, Issue 11, March 17; Page: 2957-2962, DOI:10.14260/jemds/2014/2229

ABSTRACT: PURPOSE: The objectives of this study were to compare the effects of caudal dexmedetomidine combined with Ropivacaine to provide postoperative analgesia in children and also to establish its safety in the pediatric patients. METHODS: In a randomized, prospective, parallel group, double-blinded study, 80 children of 1 year to 6years posted for lower abdominal surgeries were recruited and allocated into two groups: Group RD $(\mathrm{n}=40)$ received $0.25 \%$ Ropivacaine $1 \mathrm{ml} / \mathrm{kg}$ with dexmedetomidine $2 \mu \mathrm{g} / \mathrm{kg}$, making the volume to $0.5 \mathrm{ml}$ and Group $\mathrm{R}(\mathrm{n}=40)$ received $0.25 \%$ Ropivacaine $1 \mathrm{ml} / \mathrm{kg}+0.5 \mathrm{ml}$ normal saline. Induction of anesthesia was achieved with Inj. Ketamine $2 \mathrm{mg} / \mathrm{kg}+\mathrm{Inj}$. Succinylcholine $2 \mathrm{mg} / \mathrm{kg}$. Intubated with appropriate-sized Endotracheal tube and caudal block was performed in all patients. Maintained with $66 \%$ nitrous oxide in Oxygen and isoflurane 0.2-0.4\%.Post-operative pain assessed with FLACC score. RESULTS: The duration of postoperative analgesia recorded a mean of 339 minutes (5.6hrs $\pm 2.4 \mathrm{hrs}$.) in Group R compared with 884 minutes ( $14.7 \mathrm{hrs}$. $\pm 5 \mathrm{hrs}$ ) in Group RD, with a p value of $<0.001$. Group RD patients achieved a statistically significant higher FLACC score compared with Group RD patients. The peri-operative hemodynamics were stable among both the groups. CONCLUSION: Caudal dexmedetomidine (2 $\mu \mathrm{g} / \mathrm{kg}$ ) with $0.25 \%$ Ropivacaine $(1 \mathrm{ml} / \mathrm{kg}$ ) for pediatric lower abdominal surgeries provides significant postoperative pain relief and better quality of sleep and a prolonged duration of arousable sedation.

KEYWORDS: Analgesia, anesthesia, caudal Dexmedetomidine, ropivacaine, post-operative period.

INTRODUCTION: There has been a continuing search for a completely satisfactory method for pain relief in children. This technique need to be safe, with low incidence of side effects, and to produce analgesia of adequate duration. It's also advantageous if the technique is simple and without later complications. In the case of day care surgery an added requirement is early recovery. Children undergoing surgery for inguinal hernia, hydrocele, phimosis, undescended testis represent a large number of outpatient's surgical cases.

The traditional use of Narcotics for pain control is associated high incidence of nausea and vomiting, an increased incidence of respiratory depression and pain associated with intramuscular injection, thus delaying discharge from hospital.

The regional anesthesia has become an accepted part of anesthesia for pediatric outpatient surgery. This technique alone or combined with light General anesthesia provides significant pain relief without narcosis, while minimizing detrimental physiological alteration. It minimizes the total requirement of inhalational or intravenous anesthetic drugs, hastens awakening, allows early ambulation, and thus shortens recovery room stay. The most frequently used regional anesthetic technique in children is the caudal epidural injection, usually combined with light General anesthesia, 
thus reducing intra operative need for inhalational agents, attenuate the stress response to surgery, facilitate a rapid, smooth recovery and provide good immediate postoperative analgesia. In order to decrease intra and postoperative analgesic requirements after single shot caudal epidural blockade, various additives such as morphine, fentanyl, clonidine and ketamine with local anesthetics have been investigated. The use of caudal route ${ }^{1}$ for providing postoperative analgesia has become a standard practice in many hospitals. The ease of placing a caudal block, its safety and reliability in providing good post-operative analgesia are well known.

Ropivacaine, a long acting amide local anesthetic related structurally to bupivacaine, has been used for pediatric caudal anesthesia. It provides pain relief with less motor blockade and is less cardiotoxic than bupivacaine, which makes it a more suitable agent for caudal epidural analgesia, especially following day care surgery. Dexmedetomidine is an alpha 2 agonist having an eight fold greater affinity for alpha 2 adrenergic receptors than clonidine and much less alpha 1 effects. A major advantage of dexmedetomidine is its higher selectivity compared with clonidine for alpha $2 \mathrm{~A}$ receptors which is responsible for the hypnotic and analgesic effects. The objective of this study is to compare the effect of dexmedetomidine combined with caudal ropivacaine to provide postoperative analgesia in children undergoing lower abdominal surgeries

\section{METHODS:}

STUDY DESIGN: Randomized, prospective, parallel group, double blinded study

RANDOMISATION: Simple randomized sampling was done by lottery method

INCLUSION CRITERIA: ASA grade $1 \& 2$ patients between 1 to 6 yrs. of age undergoing lower abdominal surgeries were included.

EXCLUSION CRITERIA: Patients with known allergy to the study drugs, coagulopathy, infection at the site of caudal block, history of developmental delay, neurological diseases and skeletal deformities were excluded.

ALLOCATION: Institutional ethical committee and review board's approval obtained. After getting written informed consent from the parents, the children were randomly allocated into two groups. Group R ( $\mathrm{n}=40)$ was taken as Ropivacaine group and Group RD ( $\mathrm{n}=40)$ as Ropivacaine + Dexmedetomidine group.

\section{STUDY GROUPS:}

Group R: ( $\mathrm{n}=40)$ caudal $0.25 \%$ Ropivacaine $1 \mathrm{ml} / \mathrm{kg}+0.5 \mathrm{ml} \mathrm{NS}$.

Group RD: $(\mathrm{n}=40)$ 0.25\%Ropivacaine $1 \mathrm{ml} / \mathrm{kg}$ with Dexmedetomidine $2 \mathrm{mcg} / \mathrm{kg}$, making the volume to $0.5 \mathrm{ml}$

MASKING: The Anesthesiologist who administered the drug and the observer were blinded to the study. Sterile syringes containing drug were loaded by another anesthesiologist not participating in study. Intraoperative monitoring and post-operative observation was done by the same anesthesiologist who administered the caudal but was unaware of the content of the syringes. 
PRE OPERATIVE EVALUATION: Age, Body weight and baseline vital parameters of all children were recorded. Relevant history were recorded. Complete physical examination and airway assessment were done. Blood Hemoglobin percentage, blood sugar, urea, serum creatinine and urine analysis were done. All patients were premedicated with oral midazolam $0.5 \mathrm{mg} / \mathrm{kg} 1$ hour prior to induction. Induction was done with Inj. ketamine $2 \mathrm{mg} / \mathrm{kg}+$ Inj. Suxamethonium $2 \mathrm{mg} / \mathrm{kg}$. Appropriate sized endotracheal tube were inserted. Anesthesia was maintained with $66 \% \mathrm{~N}_{2} \mathrm{O}$ in oxygen and isoflurane 0.2-0.4\%.Caudal block was performed in left lateral position in all patients according to the group. No other narcotics, sedatives or analgesics were used intraoperatively. Standard monitoring done during anesthesia and surgery. Heart rate, Mean arterial pressure, and Oxygen saturation were recorded before surgery and every $5 \mathrm{~min}$ till the end of surgery.

\begin{tabular}{|l|c|c|}
\hline \multicolumn{1}{|c|}{ Surgery } & Group R & Group RD \\
\hline Inguinal hernia & $15(37.5 \%)$ & $15(37.5 \%)$ \\
\hline Circumcision & $10(25 \%)$ & $10(25 \%)$ \\
\hline Urethroplasty & $6(15 \%)$ & $6(15 \%)$ \\
\hline Cystolithotomy & $4(10 \%)$ & $5(12.5 \%)$ \\
\hline Orchidopexy & $5(12.5 \%)$ & $4(10 \%)$ \\
\hline \multicolumn{2}{|c|}{ TABLE 1: SURGICAL PROCEDURES }
\end{tabular}

Using the FLACC pain score (Table 2) each patients pain intensity was assessed at the end of surgery and then at $2 \mathrm{hrs}, 4 \mathrm{hrs}, 6 \mathrm{hrs}, 8 \mathrm{hrs}, 12 \mathrm{hrs}$, $16 \mathrm{hrs}$, 20hrs after operation. If the FLACC pain score was 4 or more syrup paracetamol $15 \mathrm{mg} / \mathrm{kg}$ was administered. The duration of analgesia was also recorded (Figure 1) (from the time of caudal injection to the time at which FLACC score was 4 or more). Complications such as postoperative nausea and vomiting (PONV), Respiratory depression, urinary retention, hypotension and bradycardia were also noted. Respiratory depression was defined as a decrease in oxygen saturation of less than 95\% requiring supplemental oxygen. Bradycardia was defined as HR below 80beats per minute for $<1$ year, below 60 beats per minute for ages $>1$ year.Failure of caudal block was defined as any increase in HR or MAP more than $20 \%$ of the pre incision values. In our study we encountered 3 failed caudal blocks. These cases were eliminated from the study.

\begin{tabular}{|c|l|c|}
\hline Parameter & \multicolumn{1}{|c|}{ Finding } & Points \\
\hline \multirow{3}{*}{ Face } & No particular expression or smile & 0 \\
& Occasional grimace or frown withdrawn, disinterested & 1 \\
& Frequent to constant quivering chin, clenched jaw & 2 \\
\hline \multirow{3}{*}{ Leg } & Normal position or relaxed & 0 \\
& Uneasy, restless, tense & 1 \\
& Kicking or legs drawn up & 2 \\
& Lying quietly, normal position, moves easily & 0 \\
Activity & Squirming, shifting back and forth, tense & 1 \\
& Arched, rigid or jerking & 2 \\
\hline
\end{tabular}




\begin{tabular}{|c|l|l|}
\hline \multirow{3}{*}{ Cry } & No cry(awake or asleep) & 0 \\
& $\begin{array}{l}\text { Moans or whimpers occasional complaints } \\
\text { Crying steadily, screams or sobs, frequent complaints }\end{array}$ & 1 \\
\hline \multirow{3}{*}{ Consolability } & $\begin{array}{l}\text { Content relaxed } \\
\text { Reassured by occasional touching hugging or } \\
\text { being talked to, distractable } \\
\text { Difficult to console or comfort }\end{array}$ & 0 \\
\hline
\end{tabular}

Table 2: FLACC SCORE TO ASSESS POST OPERATIVE ANALGESIA²
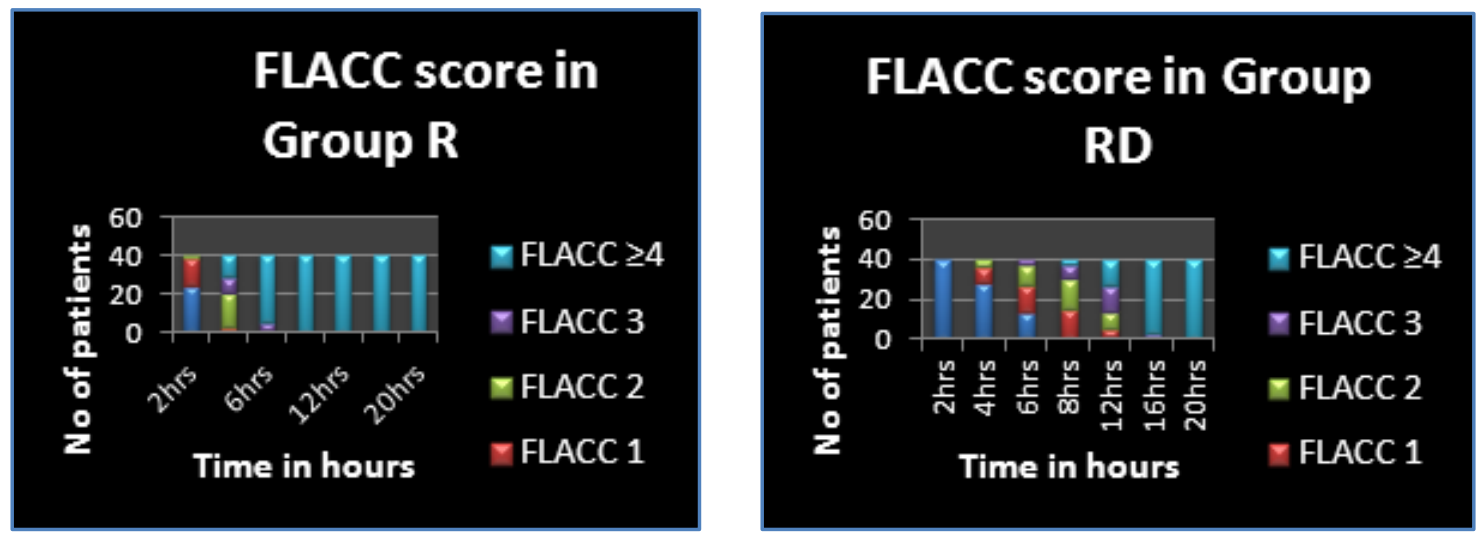

FIGURE 1: FLACC SCORE

STATISCAL ANALYSIS: Done with unpaired student $t$ test. $p$ value of $<0.001$ was considered highly significant.

RESULTS: The duration of post-operative analgesia recorded a mean of 339 minutes (5.6 \pm 2.4 hours) and in Group R compared with 884 minutes (14.7 \pm 5 hours) in Group RD, with a p value of $<0.0001$. There was a significant difference between the groups in the FLACC score measured in the postoperative period. Group R patients achieved significantly higher FLACC score compared with Group RD patients, Where 35 out of 40 children achieved a FLACC score of 4 at $6^{\text {th }}$ hour compared with 0 patients in Group RD children, whereas group RD children had FLACC score of 4 at $16^{\text {th }}$ hour of postoperative period (Figure 1).R group children were agitated and restless compared to RD group children who were calm and co-operative. The pre-op, intra-op and post-operative hemodynamic changes between the groups were comparable and were not statistically significant and therapeutic interventions were not required.

DISCUSSION: When compared to Bupivacaine, Ropivacaine has a wide margin of safety, less motor blockade, ${ }^{3,4}$ less cardiovascular or neurological toxicity ${ }^{5}$ but has same duration of action. It can be used safely for regional anesthesia and analgesia in pediatrics.

Dexmedetomidine enhances the effects of local anesthetics without increasing the adverse effects. Respiratory effects are also minimal. When compared to Clonidine, Dexmedetomidine is a more selective alpha 2 adrenoreceptor agonist, it allows its uses in high doses without the adverse vascular effects of activation of alpha 1 receptors. Its sedative effect can be reversed by atipamezole. These properties make Dexmedetomidine useful for sedation and analgesia during the whole 
perioperative period. Routes of administration are Intravenous, Intrathecal, epidural. More recently investigations in children have described the pharmacokinetics as well as a number of pharmacodynamic effects in controlled trials. Dexmedetomidine provides sedation that permits arousal with gentle stimulation.

Et-Hennawy et al. ${ }^{6}$ administered dexmedetomidine and clonidine, both in a dose of $2 \mathrm{mcg} / \mathrm{kg}$ as adjuvant with $0.25 \%$ bupivacaine caudally. They found that the duration of analgesia was significantly higher in the group receiving bupivacaine-dexmedetomidine mixture(median (95\%CI):16 hours (14-18) or Bupivacaine-clonidine mixture (median (95\%CI):12 hours(3-21) than the group receiving bupivacaine alone (median (95\% CI):5 hours (4-6).

Neogi et $\mathrm{al}^{7}$ compared clonidine $1 \mathrm{mcg} / \mathrm{kg}$ and dexmedetomidine $1 \mathrm{mcg} / \mathrm{kg}$ as adjuncts toropivacaine $0.25 \%$ for caudal analgesia in children and concluded that addition of both clonidine and dexmedetomidine with ropivacaine administered caudally significantly increases the duration of analgesia. The patients stayed hemodynamically stable and there were no undue side effects. The mean duration of analgesia was $6.32 \pm 0.46$ hours in ropivacaine group, $13.17 \pm 0.68$ hours in clonidine group and $15.26 \pm 0.86$ hours in dexmedetomidine group. The prolongation of duration of analgesia was significant in both clonidine and dexmedetomidine groups when compared to ropivacaine alone administered group. The incidence of adverse effects were statistically insignificant between these groups.

In our study the duration of postoperative analgesia in ropivacaine group is 339 minutes (5.6 hrs \pm 2.4 hours) and in ropivacaine with dexmedetomidine group 864 minutes (14.7 hours \pm 5 hours) with a $\mathrm{p}$ value of $<0.00010^{8}$. Group R patients achieved a statistically significant higher FLACC score compared with Group RD patients. The preoperative intraoperative, postoperative hemodynamic variables between the groups were comparable and were not statistically significant and therapeutic interventions were not required. No episodes of clinically significant postoperative complications such as PONV, respiratory depression, urinary retention, bradycardia, urinary obstruction were observed. Dexmedetomidine provides a prolonged post-operative analgesia, and it has a good safety profile. It provides stable hemodynamics. It is in concordance with the reports published by other studies.

CONCLUSION: Addition of dexmedetomidine $2 \mathrm{mcg} / \mathrm{kg}$ with $0.25 \%$ ropivacaine $1 \mathrm{ml} / \mathrm{kg}^{9}$ provided significantly prolonged post-operative analgesia upto 14.5 hours, and it provided a better quality of sleep. Perioperative hemodynamics were stable. No episodes of post-operative complications were observed. With this we conclude that dexmedetomidine is a safe and effective adjuvant for caudal analgesia in pediatric patients.

\section{REFERENCES:}

1. Fortuna A. Caudal analgesia: A simple and safe techniques in paediatric surgery: BJA, 1967, 39, 165-66.

2. Merkel SI, Voeoel-Lewus, Malviya S. The FLACC: A behavioral scale for scoring postoperative pain in young children. Pedia Nurs 1997; 23:293-7.

3. Breschan C, Jost R, Krumpholz R, Schaumberger F, Stettner H, Marhofer P, Likar R. A prospective study comparing the analgesic efficacy of levobupivacaine, ropivacaine and bupivacaine in pediatric patients undergoing caudal blockade. Pediatric Anesthesia, Volume 15, Issue 4, pages 301-306, April 2005. 
4. Ivani G, De Negri P, Lonnqvist PA, L'Erario M, Mossetti V, Difilippo A, Rosso F. Caudal anesthesia for minor pediatric surgery: a prospective randomized comparison of ropivacaine $0.2 \%$ vs. levobupivacaine 0.2\% Paediatr Anaesth. 2005 Jun; 15(6):491-4.

5. Karmarkar MK, Aun CS, Wong EL, Wong AS, Chan SK, Yeung CK. Ropivacaine Undergoes slower systemic absorption from caudal epidural space in children than bupivacaine. Anaes Analg. 2002 Feb; 94 (2): 259-65.

6. El-Hennawy AM, Abd-Elmaksoud AM et al. Addition of clonidine or dexmedetomidine to bupivacaine prolongs caudal analgesia in children.Br J Anaesth 2009; 103:268-74.

7. Neogi M, Bhattacharjee DP et al. A comparative study between clonidine and Dexmedetomidine used as adjuvants to ropivacaine for caudal analgesia in pediatric patients. J Anaesthesiol Clinic Pharmacy 2010; 26:149-53.

8. Saadawy I et al. Effect of Dexmedetomidine on the characteristics of bupivacaine in a caudal block. Acta Anaesthesiol Scand 2009; 88; 790-6.

9. Vijay $G$ Anand et al. Effects of dexmedetomidine added to ropivacaine in paediatric lower abdominal surgeries. I J A / vol 5/Jul-Aug 2011/340-346.

\section{AUTHORS:}

1. Monika Gandhi

2. B. K. Ved

3. N. Rajakumari

\section{PARTICULARS OF CONTRIBUTORS:}

1. Associate Professor, Department of Anaesthesiology, M.G.M. Medical Collage, Indore, Madhya Pradesh.

2. Professor, Department of Anaesthesiology, M.G.M. Medical Collage, Indore, Madhya Pradesh.

3. Resident, Department of Anaesthesiology, M.G.M. Medical Collage, Indore, Madhya Pradesh.

\section{NAME ADDRESS EMAIL ID OF THE CORRESPONDING AUTHOR:}

Dr. Monika Gandhi, 91/3, Vallabh Nagar, Kalptaru, Indore, Madhya Pradesh.

E-mail: drmonikagandhi2911@gmail.com

Date of Submission: 14/02/2014. Date of Peer Review: 15/02/2014. Date of Acceptance: 27/02/2014. Date of Publishing: 17/03/2014. 